\title{
Fragility Analysis of Existing Unreinforced Masonry Buildings through a Numerical-based Methodology
}

\author{
Amin Karbassi* and Pierino Lestuzzi
}

\author{
Applied Computing and Mechanics Laboratory, École Polytechnique Fédérale de Lausanne, Station 18, 1015 Lausanne, \\ Switzerland
}

\begin{abstract}
As an approach to the problem of seismic vulnerability evaluation of existing buildings using the predicted vulnerability method, numerical models can be applied to define fragility curves of typical buildings which represent building classes. These curves can be then combined with the seismic hazard to calculate the seismic risk for a building class (or individual buildings). For some buildings types, mainly the unreinforced masonry structures, such fragility analysis is complicated and time consuming if a Finite Element-based method is used. The FEM model has to represent the structural geometry and relationships between different structural elements through element connectivity. Moreover, the FEM can face major challenges to represent large displacements and separations for progressive collapse simulations. Therefore, the Applied Element Method which combines the advantages of FEM with that of the Discrete Element Method in terms of accurately modelling a deformable continuum of discrete materials is used in this paper to perform the fragility analysis for unreinforced masonry buildings. To this end, a series of nonlinear dynamic analyses using the AEM has been performed for two unreinforced masonry buildings (a 6-storey stone masonry and a 4-storey brick masonry) using more than 50 ground motion records. Both in-plane and out-of-plane failure have been considered in the damage analysis. The distribution of the structural responses and inter-storey drifts are used to develop spectral-based fragility curves for the five European Macroseismic Scale damage grades.
\end{abstract}

Keywords: Seismic Vulnerability Assessment, Applied Element Method, Fragility Analysis, Unreinforced Masonry.

\section{INTRODUCTION}

For regions where little damage data exist, small scale experimental tests and numerical modelling methods are good substitutes for the observed damage procedures in the process of the seismic vulnerability evaluation for existing buildings such as unreinforced masonry buildings. Experimental tests for even scaled buildings can be expensive and require special equipments, and are mainly performed on individual masonry walls instead $[1,2]$. On the other hand, different numerical methodologies from simple numerical procedures (e.g. $[3,4])$ to more complex dynamic methods (e.g., $[5,6])$ are conducted to study the seismic vulnerability of existing buildings. Simple procedures have also been proposed to study the nonlinear dynamic behavior of masonry building [7]. However, in the interest of achieving a simpler model for dynamic analysis, the model developed is based on two-dimensional behavior only. Nonetheless, many buildings have irregular layouts that can result in a structure that behaves in complex three-dimensional ways under seismic loadings. Therefore, three-dimensional analysis should produce a more accurate description of the behavior of the structure during an earthquake.

*Address correspondence to this author at the Applied Computing and Mechanics Laboratory, École Polytechnique Fédérale de Lausanne, Station 18, 1015 Lausanne, Switzerland; Tel: +41 21 6936382; Fax: +41 21 6934748; E-mail: amin.karbassi@epfl.ch
This paper deals with the structural analysis of the masonry building which faces several challenges due to the progressive collapse of masonry during an earthquake. To overcome these challenges, an alternative modelling technique to the FEM is used here in combination with nonlinear dynamic analysis to consider both in- and out-of-plane behavior for masonry buildings and to include the dynamic properties in the seismic vulnerability study. The objective of this paper is to present a numerical-based methodology to develop fragility curves for unreinforced masonry buildings. Those fragility curves can be used in combination with the hazard data of a region to perform a complete seismic risk assessment for the studied buildings. Such risk analysis [8], however, is out of the scope of this paper.

\section{MATERIALS AND METHODOLOGY}

\section{Progressive Collapse in Masonry Structures}

In-plane damage mechanisms for masonry walls are governed by failure modes in flexure (rocking), shear sliding along the joints, or shear diagonal cracking [9]. The occurrence of each of those failure modes depends on several parameters such as the wall boundary conditions, the axial load of the wall, masonry geometrical characteristics and constituents. Several references discuss the tendency of the prevalence of each failure mode based on the condition/value of those parameters (e.g., $[10,11])$. It should be noted that there is not always a crystal clear certainty of the occurrence of a specific failure mode because many interactions may 
happen between them. Failure occurs in piers or spandrels based on their relative stiffness and strength $[12,13]$. In weak pier-strong spandrel, the plastic displacement due to flexure or shear is concentrated in the piers of one storey (generally the first floor) which results in a soft storey mechanism in the building. In the other damage mechanism, strong pierweak spandrel, the failure modes of spandrels can be rocking, usually occurring on top floors, or diagonal cracking, happening in mid-storeys [14].

The out-of-plane damage mechanism, on the other hand, is governed by the connection of the walls to the roof, floors, intersecting walls, the axial load level, and also the position and dimension of openings. Some of the most probable outof-plane failure mechanisms are reported in [15]. To capture those failure mechanisms in the structural analysis stage, the Finite Element Method is known as the most common method to create 3-D structural numerical models.

Using a Finite-Element-based analysis, materials are modelled as a continuum, and elements are connected at nodes; therefore, it is assumes that all elements sharing the same node have the same displacement. However, to accurately track the behavior of each element when element separation occurs in a progressive collapse analysis, elements should be considered to displace independently. An alternative is to use multiple node ID's at expected separation points; however, this technique can results in stress singularity and inaccurate stresses at locations of nodal separation which leads to an uncertain stress distribution within the whole structure. On the other hand, special techniques must be adapted to model cracks in the elements, and to consider the effect of element separation on the building's overall stiffness. One technique known as "smeared cracks" deals with cracks by considering their effect on stiffness and stress-strain equations [16]. Although showing considerable accuracy in calculating displacements and failure loads, models developed based on this method are relatively complicated. Moreover, special elements should be used in the location of dominant cracks [17]. Such a method also requires previous knowledge of the location and direction of cracks' propagation. Nonetheless, in most cases, the fracture plane is arbitrary and unknown before the analysis. The same problem exists for the technique known as "discrete cracks" modelling, in which cracks are taken into account as discrete items [18]. The latter method is more appropriate for cases with few cracks.

The elastic (or elasto-plastic) FEM analyses has been also applied in some researches for the seismic vulnerability assessment and rehabilitation of masonry buildings [19] . However, in those applications, the nonlinear behavior of the materials and consequently, of the whole structure, in a progressive collapse simulation is overlooked. Therefore, developing precise fragility curves for masonry buildings would be difficult using those methodologies.

\section{Application of the AEM for Masonry}

To overcome the above problems, the Applied Element Method (AEM) is used in this paper to perform the dynamic nonlinear analyses.. This method is based on dividing structural members into virtual elements connected through springs (Fig. 1). This means that unlike FEM, there are no common nodes between elements. Therefore, large displacements and elements progressive separation can be simulated through successive failure of those springs [20].

Normal and shear springs located at the element contact points, distributed around the edges, as shown in Fig. (1), represent stresses, strains, and deformations of certain portions of the structure. Fig. (2) shows an example of the configuration of springs between two elements, extended from the centerline of one element to the centerline of the adjacent one. Those springs can simulate joint de-bonding, shear sliding and direct tension. Furthermore, partial connectivity between elements is allowed during the analysis: while some of the springs fail, others are still effective. For the normal and shear springs inside the hatched area in Fig. (2) the stiffness is determined as follow.

$K_{n}=\frac{E \cdot a \cdot t}{d}, K_{s}=\frac{\text { G.a.t }}{d}$

In this equation, $a$ is the distance between the springs, $d$ is the length of the represented area by each spring which is actually the element's length, $t$ is the thickness of the element, and $E$ and $G$ are the Young's and shear modulus of the material, respectively.

To apply the AEM method for masonry, masonry is discretized such that brick units are represented by number of small elements with mortar joint at their corresponding edges. Principal stress failure criterion is used for units and Mohr-Coulomb's friction model with tension cut-off is implemented to model interface behavior including mortar. Furthermore, to describe the shear behavior in tensile regime, formulation of softening in the process of loss of cohesion and de-bonding is applied [22]. Two types of springs are needed to represent bricks and the brick-mortar interaction, as shown in Fig. (3). If the crack passes through the bed or head joints, the brick-mortar springs are affected. On the

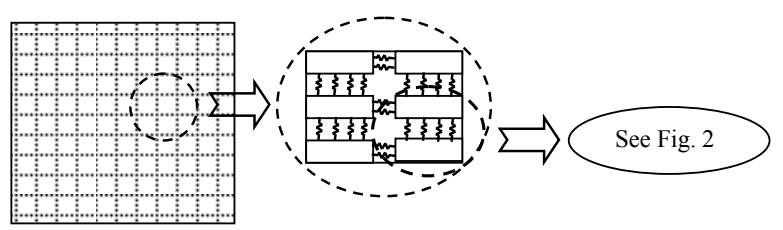

$\begin{array}{ll}\text { (a) Element generation } & \text { (b) Spring distribution }\end{array}$

Fig. (1). Modelling an element in AEM.

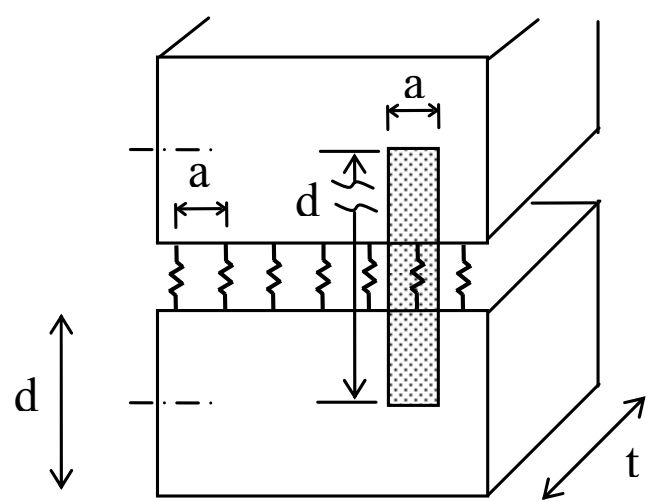

Fig. (2). Spring distribution and area of influence of each springs pair in AEM Adapted from [21]. 
other hand, if the crack passes directly through bricks, the failure is modelled using the failure of the brick springs. The stiffness of springs which simulate forces and displacements in bricks is calculated from Equation 1 as they connect elements of identical materials. For brick-mortar springs, however, the equivalent normal and shear stiffness is calculated based on a series system of springs, shown in Fig. (3). The equivalent normal and shear stiffnesses are therefore calculated as follow.

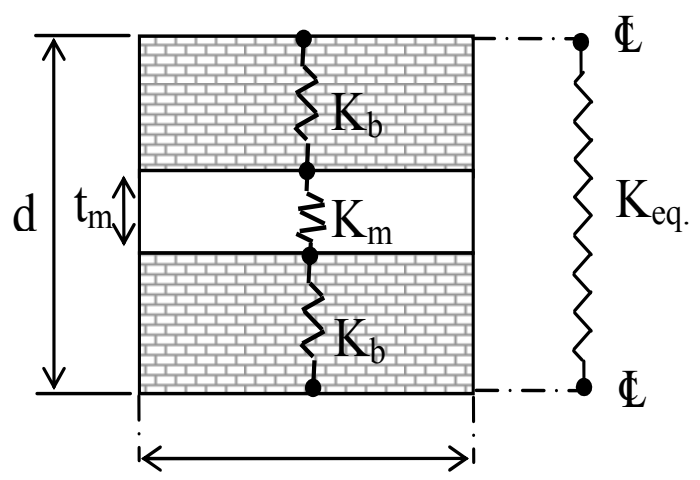

a

Fig. (3). Modeling masonry in AEM.

$$
\frac{1}{K n_{\text {eq. }}}=\frac{d-t_{m}}{E_{b} \times a \times t}+\frac{t_{m}}{E_{m} \times a \times t},
$$

and

$$
\frac{1}{K s_{e q .}}=\frac{d-t_{m}}{G_{b} \times a \times t}+\frac{t_{m}}{G_{m} \times a \times t}
$$

Where $E_{b}, G_{b}, E_{m}$, and $G_{m}$ are the brick's and mortar's Young and shear modulus, respectively. $t_{m}$ is the mortar thickness. Fig. (4) illustrates two elements connected by one pair of normal and shear springs at a general point. Three degrees of freedom are assumed for each element, one for rotation and two for translation in $\mathrm{X}$ and $\mathrm{Y}$ directions. The components of the stiffness matrix is determined by calculating the forces required at the centroid of each element to restrain all other degrees of freedom, and to satisfy equilibrium conditions against the unit displacement at the corresponding degree of freedom. More information about the stiffness matrix can be found in [20].

In a seismic vulnerability evaluation process, the calculated responses are sensitive to the characteristics of the individual ground motion used as the seismic input. Therefore, different ground motion records are required to obtain a good estimation of the building's responses. To apply the Applied Element Method in the nonlinear dynamic procedure, large deformations of an element under dynamic loads are calculated by the following general dynamic equation of motion [17].

$$
\left.[M]\rfloor \Delta U^{\prime \prime}\right]+[C]\left\lfloor\Delta U^{\prime}\right]+[K][\Delta U]=[\Delta f(t)]+\left[R_{m}\right]+\left[R_{G}\right]
$$

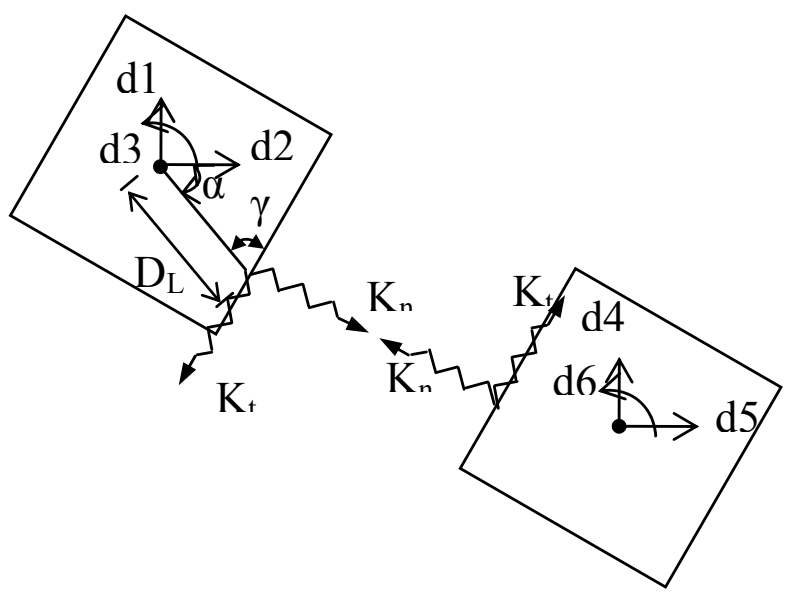

Fig. (4). Element shape, contact points, and degree of freedom.

In Equation 4, $[M]$ is the mass, $[C]$ is the damping, and $[K]$ is the stiffness matrix. Moreover, $\Delta f(t)$ is the incremental applied load vector, $[\Delta U]$ is the incremental displacement vectors, and $\left[\Delta U^{3}\right]$ and $\left[\Delta U^{\prime \prime}\right]$ are the incremental velocity and acceleration vectors, respectively. The vector $R_{m}$ in Equation 4 stands for the residual forces caused by cracking, or the incompatibility between strains and stresses at the spring location due the nonlinear behavior of materials. The vector $R_{G}$, on the other hand, represents the residual forces caused by geometrical changes of the structure during loading. In that regard, the AEM has an advantage over the FEM, noting that the latter considers the redistribution of internal forces resulting from geometrical changes by adopting a geometrical stiffness matrix. The nonlinear material behavior in the AEM is taken into account in calculating [K] and $\mathrm{R}_{\mathrm{m}}$.

Considering the structural boundaries and the load conditions in the piers and spandrels, three failure modes in masonry units are considered in the AEM (shown in Fig. 5): (1) joint de-bonding, (2) bricks sliding along bed or head joints, (3) brick cracking under direct tension. Those failure modes can be simply modelled using the two types of springs that are considered for the bricks and mortar interfaces. For instance, failure modes 1 and 2 in Fig. (6) should be reflected in brick-mortar springs and failure mode 3 should be modelled with brick springs. Consequently, the basic failure modes for piers and spandrels (e.g., shear, sliding shear, or bending) can be modelled in the AEM using a combination of those three basic failure modes in Fig. (6).
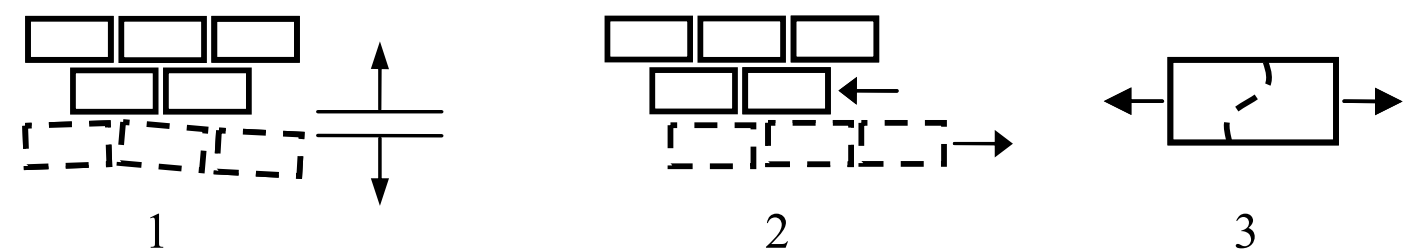

Fig. (5). Dominant failure modes in masonry units: (1) joint de-bonding, (2) units sliding along bed or head joints, and (3) unit cracking under direct tension. 


\section{DIFFERENCES OF AEM WITH DISCRETE ELE- MENT METHOD}

Discrete Element-based methods have been applied in several studies to study the in-plane behavior of masonry walls $[23,24]$. It is important to note that DEM depends on Newton's second law; therefore, everything is variable in time. Consequently, to perform a static analysis, special techniques such as applying the own weight in a long period of time with a high damping (which is not really static) should be applied. Moreover, there is no stiffness matrix using DEM, while there is a global stiffness matrix using AEM. On the other hand, time steps in DEM are calculated using Explicit Dynamics (controlled by the element size, material, and mass) while in AEM, the time step is based on the structure and phenomenon to be solved.

Unlike the Rigid Body Spring Model (RBSM) where the macro elements are connected to each other by two normal springs and one shear spring at each side [25], AEM uses distributed springs between elements. Therefore, AEM is far advanced in terms of applications to buckling, post-buckling and collision between elements.

DEM has been applied to assess the out-of-plane behavior of masonry walls [26]. To this end, masonry walls are modelled as macro-blocks subjected to out-of-plane loading.
Therefore, the local damage in the masonry walls is not considered. Moreover, such an assumption would not allow considering simultaneous in-plane behavior. On the contrary, using AEM, in-plane and out-of-plane behavior can be considered at the same time.

\section{Selection of Prototype Buildings}

\section{Stone Masonry Building (Abbreviated Hereafter CHB30)}

The first structure is a stone masonry building with concrete slabs (Fig. 6.a and Table 1) located in Lausanne. It is a $14 \mathrm{~m}$ by $12 \mathrm{~m}$ (in plan) rubble stone masonry with a total of 6 storeys. The building has 14 walls in the longitudinal direction and 15 walls in the transversal direction. The width of the walls varies between $25 \mathrm{~cm}$ to $60 \mathrm{~cm}$, and its average storey height is 3 meters. Based on the available drawings, the thickness of the slab is assumed to be $20 \mathrm{~cm}$.

\section{Brick Masonry Building (Abbreviated Hereafter YVR14)}

The second building is a brick masonry structure with RC slabs (Fig. 6.b and Table 1). This 4-storey building is located in Yverdon-Les-Bains. The building is $30 \mathrm{~m}$ by $12 \mathrm{~m}$ (in plan) and it has 37 walls in the longitudinal direction and 16 walls in the transversal direction. The storey height is $2.7 \mathrm{~m}$. The concrete slabs are considered to have a thickness of $20 \mathrm{~cm}$.

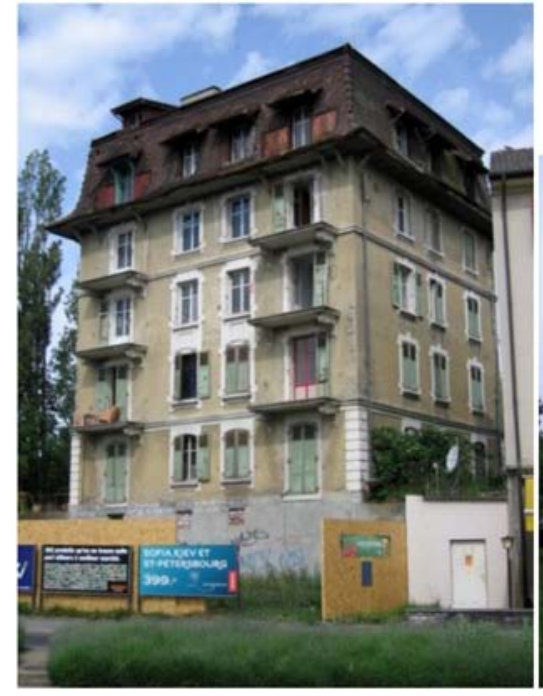

(a)

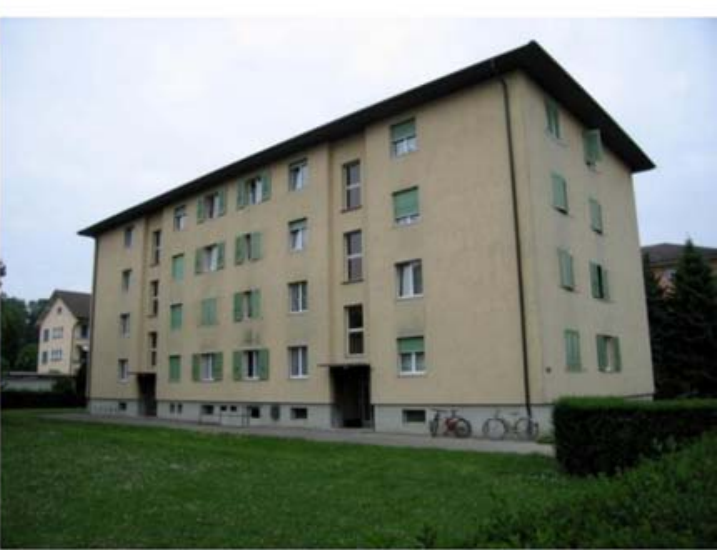

(b)

Fig. (6). Selected unreinforced masonry buildings (a) CHB30 and (b) YVR14.

Table 1. Structural Characteristics of the Buildings

\begin{tabular}{|c|c|c|}
\hline & CHB30 & YVR14 \\
\hline Number of stories & 6 & 4 \\
\hline Year of construction & End of $19^{\text {th }}$ century & 1940’s \\
\hline Structural system & Stone masonry & Brick masonry \\
\hline Floor material & $\mathrm{RC}$ & $\mathrm{RC}$ \\
\hline $1^{\text {st }}$ mode freq. ${ }^{1}$ (longitudinal) & $3.4 \mathrm{~Hz}$ & $5 \mathrm{~Hz}$ \\
\hline $2^{\text {st }}$ mode freq. ${ }^{1}$ (transverse) & $3.3 \mathrm{~Hz}$ & $5 \mathrm{~Hz}$ \\
\hline
\end{tabular}

${ }^{1}$ From ambient vibration tests 
The analyses have been carried out using AEM-based software [27]. For the studied unreinforced masonry buildings, a total number of 5 springs is used on each face of the elements. The size of the meshing is selected to avoid creating elements with large aspect ratios. To this end, approximately 22500 and 83500 elements are used for CHB30 and YVR14, respectively. As damage to the slabs is of less interest, in comparison to the masonry walls, a course mesh is chosen for the concrete floors.

\section{MATERIAL PROPERTIES}

Table 2 gives the masonry unit design properties from different references.

From [24] it is seen that

$$
f_{x k}=\frac{\gamma_{m}}{\eta_{1} \cdot \eta_{2}} f_{x d}
$$

where $f_{x k}$ and $f_{x d}$ are the characteristic and design strength values perpendicular to bed joints, respectively. $\gamma_{m}$ is the partial factor taking into account the approximation of the resistance model, as well as the differences in material properties compared to their characteristic values. $\eta_{1}$, on the other hand, is the conversion factor taking into account the decrease of $f_{x d}$ in the header and stretcher masonry. Finally, $\eta_{2}$ is the conversion factor to consider the increase in $f_{x d}$ in case of a solicitation of a localized area. From the same reference, for the benchmark buildings, $\gamma_{\mathrm{m}}=2.0$, and $\eta_{1}=\eta_{2}=1.0$.

$f_{k}=2 f_{d}$

According to Eurocode [25], characteristic values of masonry properties can be considered as the $5 \%$ percentile of the expected values. For a normal distribution of the material properties:

$$
f_{x k}=X_{5 \%}=\mu-1.65 \sigma
$$

where $\mu$ and $\sigma$ are the mean and standard deviation of the expected material properties. Considering a coefficient of variation (COV) of 0.2 (from literature), it is seen that:

$\mu=1.98 f_{x k}=3.96 f_{x d}$

Replacing the values in Table 2 in Equation 8, the expected masonry unit properties that are used in the dynamic analysis in this project are shown in Table 3 . It should be noted that the elastic modulus for masonry is reduced by $50 \%$ to consider the cracking in the masonry units in the existing buildings [4].

Table 2. Masonry Unit Design Properties

\begin{tabular}{|l|c|}
\hline$E_{m}$ modulus of elasticity & $1000 \mathrm{f}_{\mathrm{xd}}[28,29]$ \\
\hline$f_{x d}$ compression strength $(\mathrm{MPa})$ & $2-5.5[28,30]$ \\
\hline$f_{y d}$ compression strength $(\mathrm{MPa})$ & $0.3 f_{x d}-0.5 f_{x d}[28]$ \\
\hline$f_{t d}$ tensile strength $(\mathrm{kPa})$ & $150-350[31]$ \\
\hline
\end{tabular}

Table 3 Expected Properties of Masonry Units Used in the Dynamic Analyses

\begin{tabular}{|l|c|c|}
\hline & CHB30 & YVR14 \\
\hline \hline Masonry modulus of elasticity (MPa) & 1500 & 2000 \\
\hline Compression strength (MPa) & $10(\perp$ bed joints $)$ \\
& $4.2(\perp$ head joints $)$ & $10(\perp$ bed joints $)$ \\
$6.3(\perp$ head joints $)$
\end{tabular}

Table 4. Description of the Damage Grades for URM Buildings According to EMS-98 [32]

\begin{tabular}{|l|l|}
\hline \multicolumn{1}{|c|}{ Damage Grade } & \multicolumn{1}{c|}{ Description of Damages } \\
\hline \hline D1 & $\begin{array}{l}\text { Negligible to slight damage: no structural damage, slight non-structural damage: Hair-line cracks in very few walls. Fall of } \\
\text { small pieces of plaster only. Fall of loose stones from upper parts of buildings in very few cases. }\end{array}$ \\
\hline D2 & $\begin{array}{l}\text { Moderate damage: slight structural damage, moderate non-structural damage: Cracks in many walls. Fall of fairly large pieces } \\
\text { of plaster. Partial collapse of chimneys. }\end{array}$ \\
\hline D3 & $\begin{array}{l}\text { Substantial to heavy damage: moderate structural damage, heavy non-structural damage: Large and extensive cracks in most } \\
\text { walls. Roof tiles detach. Chimneys fracture at the roof line; failure of individual non-structural elements (partitions, gable walls). }\end{array}$ \\
\hline D4 & $\begin{array}{l}\text { Very heavy damage: heavy structural damage, very heavy non-structural damage: Serious failure of walls; partial structural } \\
\text { failure of roofs and floors. }\end{array}$ \\
\hline D5 & Grade 5: Destruction (very heavy structural damage): Total or near total collapse. \\
\hline
\end{tabular}




\section{Definition of Damage Grades in Masonry Buildings}

To conduct the seismic vulnerability evaluation for the studied buildings in this project, a clear definition of the damage grades is essential. The EMS-98 [32] damage grades are used in this research work to determine the limit states from the dynamic analysis. In this way, the obtained results would be in accordance with the existing EMS-based methodologies in Switzerland. Table 3 presents the description of those damage grades for masonry buildings. As the descriptions in Table $\mathbf{4}$ may be too subjective and depend too much on the personal judgment, interpretations for those damage grades in [4] are used as shown in Table 5. Consequently, material properties in Table $\mathbf{3}$ are used to determine damage grades in the dynamic analyses.

Table 5. Description of EMS-98 Damage Grades for URM According to [4]

\begin{tabular}{|c|c|}
\hline Damage Grade & Description of damages \\
\hline \hline D1 & First wall reaching the onset of cracking \\
\hline D2 & First wall reaching the yield displacement \\
\hline D3 & $\begin{array}{c}\text { Slope of the capacity curve tends to zero (Yielding } \\
\text { in majority of walls) }\end{array}$ \\
\hline D4 & Failure of the first wall \\
\hline D5 & Drop of the capacity curve \\
\hline
\end{tabular}

\section{Selection of the Ground Motion Records}

The ground motion records used in this project are chosen from the European ground motion record database with a condition of selecting those which have spectral acceleration values close to the spectral acceleration values provided by the Swiss Seismological Service for different cities in Switzerland. Table 5 presents the characteristics of the ground motion records used in the dynamic analyses of this research. The number of the analyses is more than the number of the ground motion records as in some cases, a magnified version of the ground motion records have been used to obtain damage grades 4 and 5 in the studied buildings. It should be noted that the duration stated in Table $\mathbf{6}$ for each ground motion record is the length of the record that has been used in the nonlinear dynamic analysis. Fig. (7) illustrates the distribution of the magnitude-distance to site for the ground motion records in Table 6.

\section{Development of Fragility Curves}

The fragility curve for a building presents the probability of exceeding damage grade DG, given engineering demand parameter EDP (e.g., spectral acceleration or spectral displacement). Therefore, the fragility curves for the masonry buildings here are presented in the form of a two-parameter lognormal distribution function as follows.

$F(X)=P(d>D)=\Phi\left[\frac{\ln (X)-\mu}{\sigma}\right]$

In Equation 9, $\Phi$ is the normal cumulative distribution function, $\mathrm{X}$ is the distributed engineering demand parameter

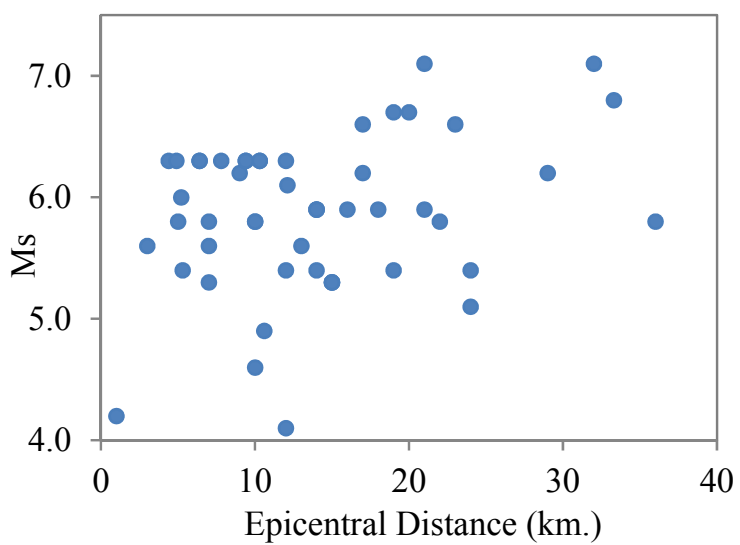

Fig. (7). Magnitude-distance distribution of the ground motion records.

(e.g., $\mathrm{S}_{\mathrm{a}}$ ), and $\mu$ and $\sigma$ are the median and standard

deviation of the natural logarithm of the engineering demand parameters, respectively. As the available hazard data in Switzerland is in the form of spectral acceleration values, $S_{a}$ is used in this report as the engineering demand parameter for the fragility curves. The distribution of the spectral acceleration values for each damage grade is given.

It should be noted that the only uncertainty considered in developing the fragility curves in this paper is the uncertainty of the record-to-record variability. Such an uncertainty is taken into account by applying the ground motion record in Table 6, in the dynamic analysis. Other sources of uncertainties such as the variability in the material properties and numerical modeling have not been taken into account here.

\section{RESULTS}

\section{Dynamic Analyses for the Building CHB30}

A total number of 61 3D-dynamic analyses were performed for the building CHB30 using the ground motion records in Table 6. An example of the damage grade 5 for CHB30 is shown in Fig. (8).

Fig. (9) shows the distribution of the damage grades with the spectral acceleration of the ground motion records. Considering that both components of the records are used simultaneously in the dynamic analysis, $S_{a}\left(T_{1}\right)$ in Fig. (9) is the geometrical means of the spectral acceleration values from both $\mathrm{X}$ and $\mathrm{Y}$ directions. The lognormal distribution of the data in Fig. (8) is used to develop the fragility curves for the building.

\section{Dynamic Analysis for the Building YVR14}

A total number of 74 3D-dynamic analyses were conducted for the building YVR14 using the ground motion records in Table 6. An example of the damage grade 5 for this building is shown in Fig. (10).

The distribution of the damage grades with the spectral acceleration of the ground motion records is shown in Fig. (11). 
Table 6. Characteristics of Ground Motion Records Used in the Nonlinear Dynamic Analyses

\begin{tabular}{|c|c|c|c|c|c|c|c|}
\hline & No. & $\mathbf{M}_{\mathrm{s}}$ & R (km) & Duration (sec.) & PGA (g) & Soil & Site \\
\hline \multirow{27}{*}{ 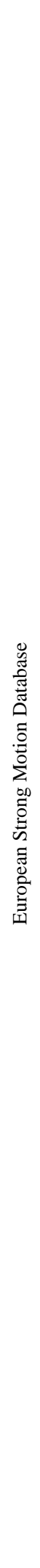 } & 55 & 6.6 & 23 & 15 & 0.36 & Rock & Friuli \\
\hline & 123 & 5.3 & 15 & 15 & 0.13 & Stiff & Friuli $^{1}$ \\
\hline & 126 & 5.9 & 21 & 10 & 0.45 & Stiff & Friuli $^{1}$ \\
\hline & 146 & 5.9 & 14 & 15 & 0.35 & Stiff & Friuli $^{1}$ \\
\hline & 171 & 5.9 & 18 & 18 & 0.15 & Stiff & Basso Tirreno \\
\hline & 175 & 6.2 & 29 & 30 & 0.14 & Soft soil & Volvi \\
\hline & 198 & 7.1 & 21 & 18 & 0.18 & Rock & Montenegro \\
\hline & 242 & 5.8 & 5 & 16 & 0.15 & Rock & Valnerina \\
\hline & 246 & 5.8 & 22 & 16 & 0.06 & Rock & Valnerina \\
\hline & 290 & 7.1 & 32 & 36 & 0.32 & Rock & Campano Lucano \\
\hline & 333 & 6.7 & 20 & 15 & 0.23 & Soft & Alkion \\
\hline & 334 & 6.7 & 19 & 15 & 0.29 & Soft & Alkion \\
\hline & 361 & 5.4 & 19 & 16.5 & 0.21 & Stiff & Umbria \\
\hline & 365 & 5.9 & 5 & 14 & 0.1 & Rock & Lazio Abruzzo \\
\hline & 591 & 5.6 & 3 & 14 & 0.26 & Soft & Umbria Marche \\
\hline & 593 & 5.6 & 13 & 15 & 0.54 & Stiff & Umbria Marche \\
\hline & 622 & 5.3 & 7 & 15 & 0.13 & Soft & Umbria Marche $^{1}$ \\
\hline & 766 & 5.4 & 12 & 15 & 0.32 & Rock & Umbria Marche $^{1}$ \\
\hline & 948 & 5.4 & 24 & 15 & 0.25 & Soft & Sicilia-Orientale \\
\hline & 990 & 5.3 & 15 & 12.6 & 0.13 & Rock & Lazio Abruzzo $^{1}$ \\
\hline & 1313 & 5.9 & 16 & 12 & 0.31 & Stiff & Ano Liosia \\
\hline & 1715 & 5.9 & 14 & 12 & 0.33 & Stiff & Ano Liosia \\
\hline & 2015 & 6.2 & 9 & 12 & 0.18 & Stiff & Kefallinia $^{1}$ \\
\hline & 3802 & 5.8 & 7 & 12 & 0.47 & Rock & Tirana \\
\hline & 5651 & 5.6 & 7 & 4.5 & 0.38 & Very Soft & Benja Luka \\
\hline & 6040 & 5.4 & 14 & 9.9 & 0.13 & Stiff & Kefallinia \\
\hline & 6115 & 6.6 & 17 & 12 & 0.27 & Rock & Kozani \\
\hline
\end{tabular}


Table 6. Contd.....

\begin{tabular}{|c|c|c|c|c|c|c|c|}
\hline & No. & Ms & $\mathbf{R}(\mathbf{k m})$ & Duration (sec.) & PGA (g) & Soil & Site \\
\hline & 6131 & 4.1 & 12 & 16 & 0.28 & Soft & Lonian \\
\hline \multirow{6}{*}{ 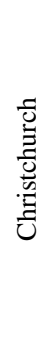 } & $\underline{\mathrm{CBGS}}$ & 6.3 & 10.3 & 22 & 0.53 & Soft & Botanic Gardens \\
\hline & CCCC & 6.3 & 7.8 & 22 & 0.48 & Soft & College \\
\hline & LPCC & 6.3 & 6.4 & 22 & 0.88 & Rock & Lyttelton Port \\
\hline & NNBS & 6.3 & 12 & 22 & 0.76 & Very Soft & Bringhton School \\
\hline & REHS & 6.3 & 9.4 & 22 & 0.72 & Soft & Resthaven \\
\hline & SHLC & 6.3 & 10.3 & 22 & 0.31 & Soft & Shirley Library \\
\hline \multirow{7}{*}{ 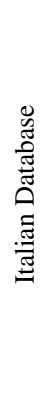 } & itaca013239 & 6.3 & 4.4 & 15.3 & 0.49 & Stiff & Aquila \\
\hline & itaca031518 & 6.0 & 5.2 & 8.5 & 0.32 & Stiff & Friuli \\
\hline & itaca072636 & 4.6 & 10 & 8 & 0.15 & Soft & Umbro-Marchigiano \\
\hline & itaca094025 & 6.1 & 12.1 & 13.7 & 0.50 & Very Soft & Umria-Marche \\
\hline & itaca174737 & 5.4 & 5 & 11 & 0.68 & Stiff & Aquila ${ }^{1}$ \\
\hline & itaca183453 & 6.8 & 33.3 & 24.8 & 0.19 & Stiff & Irpinia \\
\hline & itaca210440 & 4.9 & 10.6 & 10 & 0.19 & Stiff & Val Nerina \\
\hline
\end{tabular}

${ }^{1}$ Aftershock

\section{Fragility Curves of the Benchmark Buildings}

The median and the standard deviation of the spectral acceleration values of ground motion records for each damage grade are calculated from Figs (7 and 9). Using Equation 9 , the fragility curves are presented in the form of a twoparameter lognormal cumulative distribution function. The fragility curves for CHB30 are developed and presented in Fig. (12).

In a similar manner, the fragility curves for YVR14 are calculated and presented in Fig. (13).

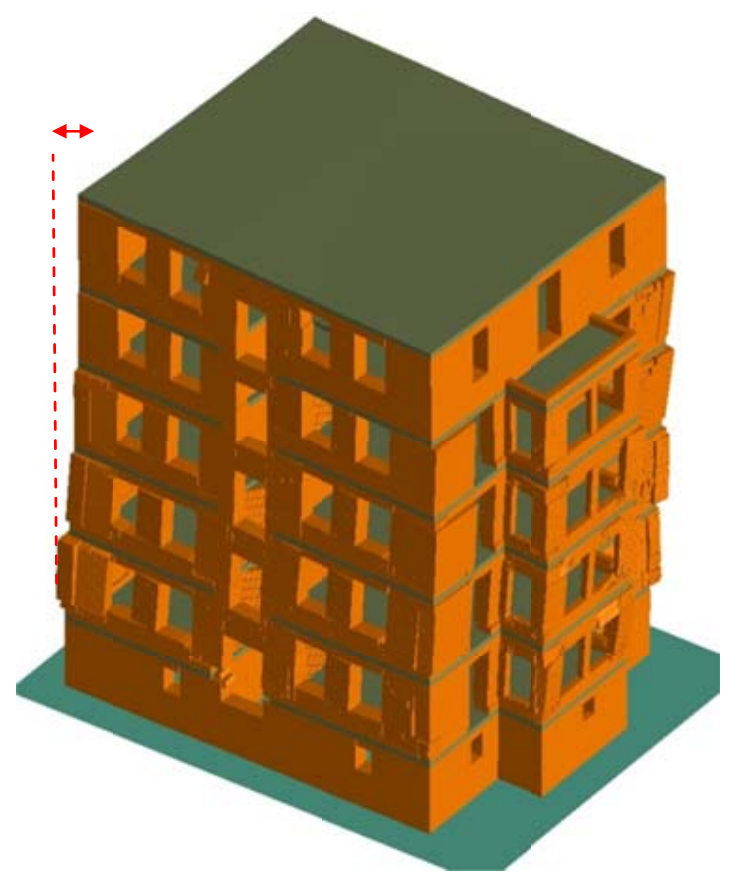

Fig. (8). DG5: collapse of CHB30 building.

\section{CONCLUSION}

A nonlinear dynamic analysis approach was used to perform the seismic vulnerability evaluation for two unreinforced masonry buildings using the Applied Element Method. 50 ground motions were used in the dynamic analyses, with an overall of 135 time-history analyses, to determine the distribution of the engineering demand parameter (the spectral acceleration values at the structure's first-mode period) at 5 damage grades. Consequently, the lognormal distribution of those measures was used to develop the acceleration-based fragility curves. The method applied in this paper is useful for the seismic vulnerability evaluation of masonry structures in regions for which little observed earthquake damage data is available. Considering the fact that each region has its exclusive building typology, the

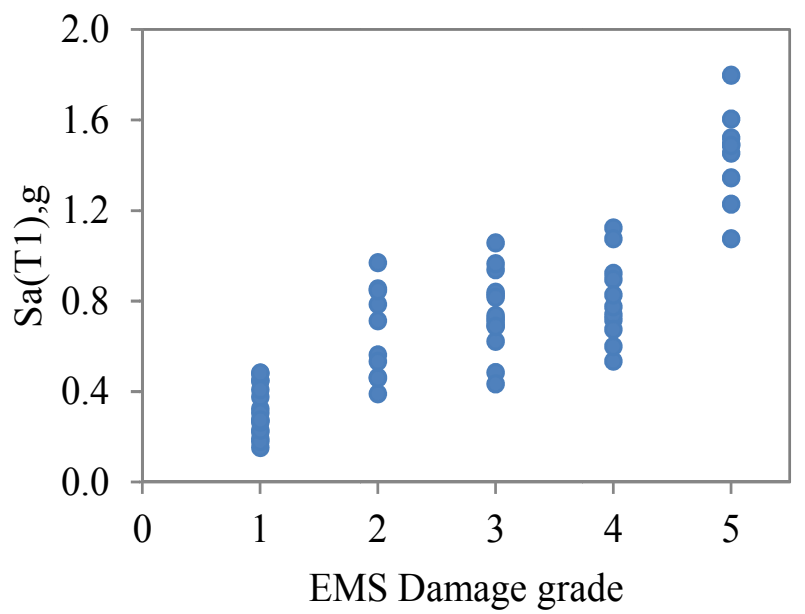

Fig. (9). Distribution of the damage grades in CHB30 with the geometrical mean of the spectral acceleration values. 


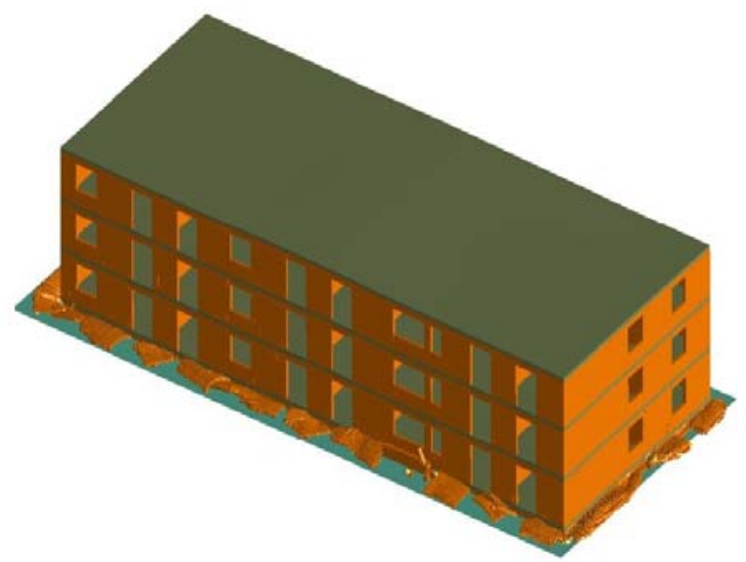

Fig. (10). DG5: collapse of the first floor in YVR14 building.

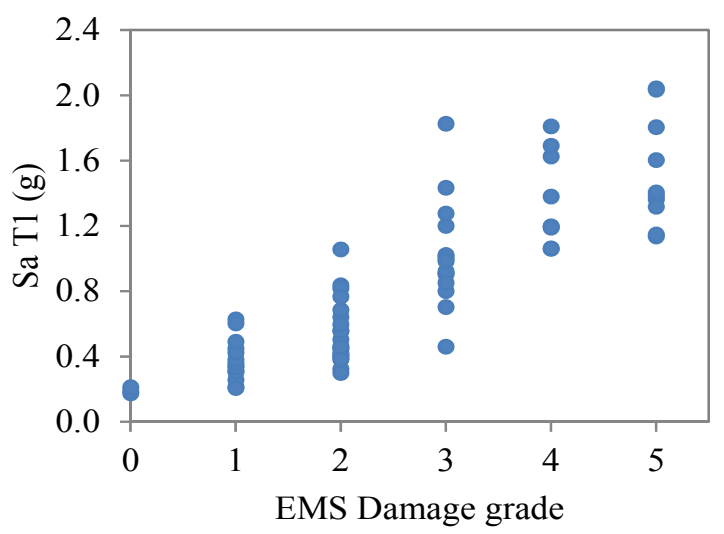

Fig. (11). Distribution of the damage grades in YVR14 with the geometrical mean of the spectral acceleration values.

evaluation process proposed in this paper which includes the development of fragility curves, can be performed elsewhere using other local data. The developed fragility curves can be directly used to perform a thorough risk analysis for both buildings.

\section{ACKNOWLEDGEMENT}

The authors are grateful for the financial support from the Swiss Federal Office for the Environment (FOEN).

\section{CONFLICTS OF INTEREST}

The authors confirm that this article content has no conflicts of interest.

\section{REFERENCES}

[1] J. Ruiz-Garcia, and M. Negrette, "Drift-based Fragility Assessment of Confined Masonry Walls in Seismic Zones”, Eng. Struct, vol. 31, pp. 125-137, 2009.

[2] M. Elgawady, P. Lestuzzi, and M. Badoux, "Dynamic versus static cyclic tests of masonry walls Before and after retrofitting with GFRP," In the 13th World Conference on Earthquake Engineering, Vancouver, B.C., Canada, 2004, Paper no. 2913.

[3] M. Oropeza, "Fragility functions for seismic risk in regions with moderate seismicity”, PhD thesis, École Polytechnique Fédérale de Lausanne (EPFL), Lausanne, Switzerland, 2011.

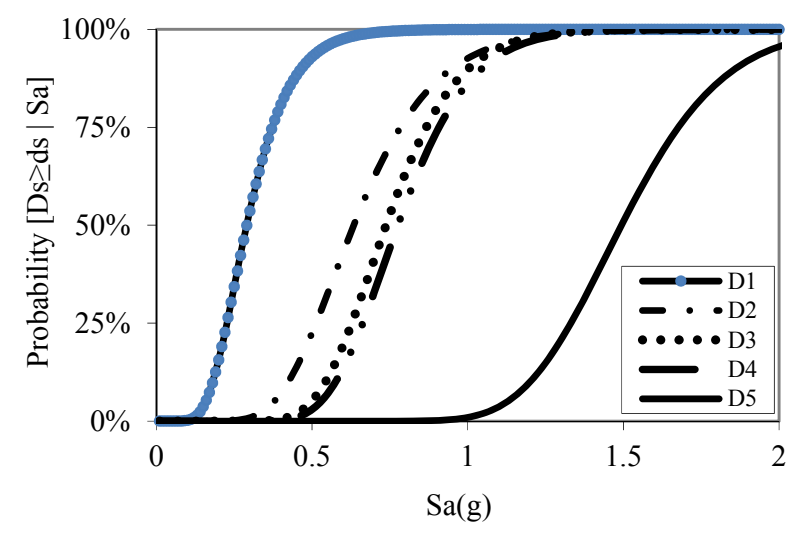

Fig. (12). Fragility curves for CHB30.

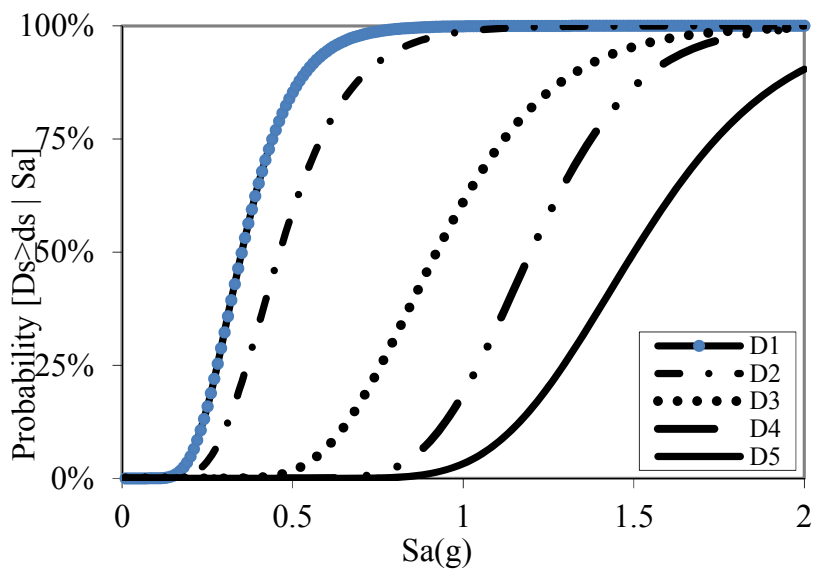

Fig. (13). Fragility curves for YVR14.

[4] K. Lang, "Seismic vulnerability of existing buildings", Ph.D. Thesis, Swiss Federal Institute of Technology, Zurich, Switzerland, 2002.

[5] M. Rota, A. Penna, and G. Magenes, "A methodology for deriving analytical fragility curves for masonry buildings based on stochastic nonlinear analyses", Eng. Struct., vol. 32, no. 5, pp. 1312-1323, 2010.

[6] A. Karbassi, "Performanced-based seismic vulnerability evaluation of existing buildings in old sectors of Quebec", $\mathrm{PhD}$ thesis, Ecole de technologie superieure, Montreal, 2010.

[7] J. Park, P. Towashiraporn, J.I, Craig, and B.J. Goodno, "Seismic fragility analysis of low-rise unreinforced masonry structures", Eng. Struct., vol. 31, no. 1, pp. 125-137, 2009.

[8] N. Jamali, and E. Kölz, "Seismic risk for existing buildings in Switzerland - development of a framework for the probabilistic risk computation, prototype and first application", Risk $\neg$ Safety AG, report prepared for Federal Office for the Environment, pp. 61, 2012.

[9] C. Calderini, S. Cattari, and S. Lagomarsino, "In-plane strength of unreinforced masonry piers”, Earthquake Eng. Struct. Dyn., vol. 38, pp. 243-267, 2009.

[10] G. Magenes, and M. Calvi, "In-plane seismic response of brick masonry walls”, Earthquake Eng. Struct. Dyn., vol. 26, pp. 10911112, 1997.

[11] V. Bosiljkov, A. Page, V. Bokan-Bosiljkov, and R. Zarnic "Performance based studies on in-plane loaded unreinforced masonry walls”, Masonry Int., vol.16, no. 2, pp. 39-50, 2003.

[12] T. Paulay, and M.J.N. Priestley, Seismic Design of Reinforced Concrete and Masonry Buildings. John Wiley and Sons, Inc.: USA 1992.

[13] Y. Belmouden, and P. Lestuzzi, "On the Seismic Vulnerability Assessment of Unreinforced Masonry Existing Buildings in Swit- 
zerland”, École Polytechnique Fédérale de Lausanne: Lausanne, Switzerland, 2007.

[14] S. Cattari, and S. Lagomarsino, "A strength criterion for the flexural behavior of spandrels in unreinforced masonry walls." In the proceeding of the $14^{\text {th }}$ World Conference on Earthquake Engineering, Beiging, 2008, Paper No. 05-04-0041.

[15] D. D'Ayala and E. Speranza, "An integrated procedure for the assessment of seismic vulnerability of historic buildings," in the Proceeding of the 12th European Conference on Earthquake Engineering, London, UK, 2002.

[16] M. Cervera, and M. Chiumenti, "Smeared crack approach: back to the original track", Int. J. Numer. Anal. Methods Geomech., vol. 30, no.12, pp. 1173-1199, 2006.

[17] H. R. Tagel-Din and K. Meguro, "Applied element method for dynamic large deformation analysis of structures.," Proceedings of JSCE Jpn. Soc. Civ. Eng., vol. 661, pp. 1(215S)-10(224S), 2000.

[18] I. Carol, P.C. Prat, and C.M. Lopez, "Normal/Shear Cracking Model: Application to Discrete Crack Analysis", J. Eng. Mech., vol. 123, no. 8, pp. 765-773, 1997.

[19] N. Ismail, H. Mahmood, H. Derakhashan, W. Clark, and J. M. Ingham, "Case study and development of retrofit application strategy for a heritage building," in $11^{\text {th }}$ Canadian Masonry Symposium Toronto, Canada, 2009, pp. C5-5.

[20] K. Meguro and H. R. Tagel-Din, "Applied Element Method Used for Large Displacement Structural Analysis," J. Nat. Dis. Sci., vol. 24, pp. 25-34, 2002.

[21] P. Mayorca, and K. Meguro, "Modeling masonry structures using the applied element method", J. Inst. Ind. Sci., Univ Tokyo, vol. 55, no. 6, pp. 581-584, 2003.

[22] B.H. Pandey and K. Meguro, "Simulation of brick masonry wall behavior under in-plane lateral loading using applied element method" in the Proceeding of the 13th World Conference on
Earthquake Engineering, Vancouver, B.C., Canada, 2004, Paper no. 1664

[23] I. Caliò, M. Marletta, and B. Panto, “A new discrete element model for the evaluation of the seismic behavior of unreinforced masonry buildings”, Eng. Struct., vol. 40, pp. 327-338, 2012.

[24] V. Sarhosis, Y. Sheng, and S.W. Garrity, "Computational Modelling of clay brickwork walls containing openings". in the Proceeding of the 8th International Masonry Conference Dresden. pp. 1743-1752, 2010.

[25] S. Casolo, and F. Pena, "Rigid element model for in-plane dynamics of masonry walls considering hysteretic behavior and damage", Earthquake Eng. Struct. Dyn., vol. 36, pp. 1029-1048, 2007.

[26] O.A. Shawa, G. de Felice, A. Mauro, and L. Sorrentino, "Out-ofplane seismic behavior of rocking masonry walls”, Earthquake Eng. Struct. Dyn., vol. 41, pp. 949-968, 2012.

[27] Applied Science International, Extreme Loading ${ }^{\circledR}$ for Structures (Version 3.1 B58), Raleigh, NC, 2010.

[28] SIA266, Masonry structures. Swiss Society of Engineers and Architects, Zurich, Switzerland, 2003.

[29] EC-6, Eurocode 6: Calcul des ouvrages en maçonnerie-partie 1-1: Règles générales pour ouvrages en maçonnerie armée et non armée. European pre-standard, European Committee for Standardisation, 2005.

[30] SIA2018, Vérification de la sécurité parasismique des bâtiments existants, Cahier technique, Swiss Society of Engineers and Architects, Zurich, Switzerland, 2004.

[31] P.B. Lourenço, "Experimental and numerical issues in the modelling of the mechanical behavior of masonry", Structural. Analysis of Historical Constructions, CIMNE; Barcelona, 1998, pp. 57-91.

[32] G. Grünthal, European Macroseismic Scale EMS-98, vol. 15. Centre Européen de Géodynamique et de Séismologie, Luxembourg, 1998.

Received: March 02, 2012

Revised: June 07, 2012

Accepted: July 11, 2012

(c) Karbassi and Lestuzzi; Licensee Bentham Open.

This is an open access article licensed under the terms of the Creative Commons Attribution Non-Commercial License (http://creativecommons.org/licenses/ by-nc/3.0/) which permits unrestricted, non-commercial use, distribution and reproduction in any medium, provided the work is properly cited. 